\title{
SABERES E PROCESSOS EDUCATIVOS NAS EXPERIÊNCIAS DE TRABALHO EM TERRITÓRIOS INSULARES
}

\author{
Maria Graça Silva \\ Universidade do Estado do Pará (UEPA), Belém, Pará, Brasil
}

\begin{abstract}
Resumo: Busca analisar saberes e processos educativos inscritos em experiências de trabalho dinamizadas por mulheres e homens que integram a Associação dos Moradores e Pequenos Produtores Rurais de João Pilatos (AMPPRJP), que no cotidiano social informam relações com a biodiversidade local, examinando perspectivas de diálogo com práticas educativas escolares do campo. Trata-se de uma comunidade insular amazônida, cujas territorialidades guardam memórias de uma ancestralidade que se efetiva por meio de uma relação intensa e sistemática com a natureza, nem sempre reconhecida e considerada pelas políticas públicas. Metodologicamente opta pelo materialismo histórico, com uso de entrevistas semiestruturadas. Os resultados da pesquisa indicam a centralidade do trabalho como um meio de sobrevivência do grupo familiar, cujas práticas produtivas são permeadas por princípios educativos e se constituem em espaços de circulação de saberes, de vivências e sociabilidades dos grupos sociais da comunidade e promovem impacto positivo nas suas realidades e aproximação e diálogo com a escola local.
\end{abstract}

Palavras-chave: Saberes do Trabalho. Processos Educativos. Territorialidade Ancestral. Biodiversidade. 
INTRODUÇÃO

O presente artigo trata de uma reflexão sobre educação trabalho e tem como foco saberes inscritos nas experiências de trabalho dinamizadas em territorialidades ancestrais insulares amazônidas, que se configuram em "maneiras de fazer" cotidianas, segundo Certeau (2000, p. 37), e apontam para perspectivas de diálogo com determinadas práticas educativas no contexto da escola do campo.

Com base nas entrevistas foi elaborado um mapeamento dos saberes que são construídos e/ou vivenciados por homens e mulheres na sua relação com diferentes contextos da biodiversidade local e que tem como centralidade práticas de trabalho, enquanto totalidade de dimensões sociais que informam a realidade das comunidades estudadas, buscando dar conta da presença ou não desses saberes no fazer pedagógico da escola local. Neste estudo,

Mapear significa reunir saberes produzidos pelos sujeitos acerca de suas práticas e/ou modos de vida, fragmentados para que possam ser potencializados e coletivizados, ou seja, mapear é buscar encontros, percursos, por entre práticas e saberes, cultura e poder (SILVA et. al., 2011, p. 66).

Trata-se de maneiras de saber-fazer que formatam uma diversidade de práticas sociais e históricas que configuram o universo de trabalho local de comunidades ribeirinhas amazônidas e seus processos de relações que estabelecem entre si e com a natureza por meio de formas de reverenciamento, apropriação, uso e/ou preservação.

Essas experiências de trabalho são compartilhadas entre os participantes, cujo processo de construção do formato de uma consciência coletiva assenta-se nas relações de parentesco, de amizade e compadrio, as quais são permeadas por práticas de solidariedade e de ajuda mútua, princípios que indicam uma preocupação com o bem comum.

As reflexões estão referenciadas em pesquisas realizadas na Ilha João Pilatos, campo empírico das investigações, localizada na região insular do município de Ananindeua, que se configura como uma diversidade socioespacial que organiza um conjunto de experiências diferenciadas de relações com a natureza, que estão associadas a conhecimentos, formas de percepção e uso de sua biodiversidade. Como um espaço de práticas de trabalho e de relações, um conjunto de saberes, imaginário e discursividades circula e é apreendido nos seus ecossistemas, reflexo da diversidade cultural que marca o contexto da Amazônia brasileira. 
Teoricamente subsidia-se, entre outros, nas reflexões de Frigotto (2001), Kosik (1995) em relação à categoria trabalho e de Brandão (2002) e Freire (1993) que fundamentam as teorias educacionais, nas quais a educação configura-se como mais um elemento da cultura, cuja análise associada ao movimento contraditório da realidade concreta e das práticas de trabalho, tem o potencial de dar conta de situações conflitantes e/ou divergentes que dificultam a transformação da realidade na qual estão inseridos os trabalhadores locais.

Parte-se do pressuposto, firmado a partir das narrativas dos moradores, de que as populações tradicionais amazônicas concebem a natureza como a extensão de suas vidas. As práticas socioculturais que desenvolvem nos seus ambientes de trabalho são construídas pelas interações com a natureza e é a partir das mesmas que são criados e recriados socializados uma série de saberes, que orientam as experiências cotidianas dos ilhéus, numa espécie de pedagogia do concreto.

Utilizou-se procedimentos da pesquisa etnográfica, como a observação participante, entrevista semi-estruturada e etnofotografia. Definiu-se como objetivo mapear saberes que são construídos e/ou vivenciados por homens e mulheres nas suas práticas de trabalho e na relação com a biodiversidade, examinando a inserção ou não desses saberes nas práticas pedagógicas da escola local e sua contribuição para a conservação dos ecossistemas locais.

Focando-se nas especificidades socioambientais das práticas de trabalho presente e/ou que se constituem no cotidiano das ilhas, tomado como um espaço educativo não formal buscou-se dar maior visibilidade àquela região insular, ainda em grande parte desconhecida não só pela comunidade acadêmica, com também pela população da grande Região Metropolitana de Belém (RMB).

Conforme (SILVA, TAVARES, 2006), a compreensão das formas pelas quais esse tipo de comunidade estrutura suas práticas de trabalho por meio de processos e formas de relações e apropriação do que dispõe a natureza e organizam-se socialmente, torna-se importante para uma aproximação dialógica entre saber constituído e saberes práticos e identificar outras possibilidades de relação sociedade e natureza a partir da contextualização da cultura local, que formata o ambiente vivido por essas pessoas.

Contudo, antes de entrar na análise dos saberes apreendidos no contexto das práticas de trabalho, esboçamos algumas notas sobre a comunidade, lócus do estudo. 
ILHA JoÃo PILATOS: UMA TERRITORIALIDADE ANCESTRAL

As comunidades de Igarapé Grande, João Pilatos e Nova Esperança, lócus de realização da pesquisa está situada na ilha de João Pilatos, que integra a região insular do município de Ananindeua região metropolitana de Belém, que associada a mais oito ilhas organizadas em comunidades formam esta região. As principais ilhas são: João Pilatos, Santa Rosa, Ilha de Sororoca, São Pedro. As comunidades mais importantes são: João Pilatos, Nova Esperança e Igarapé Grande. Essas três ilhas se destacam em relação a sua demografia e tempo de ocupação.

Na comunidade residem aproximadamente 78 famílias ribeirinhas, que estão organizadas numa Associação dos Moradores e Pequenos Produtores Rurais de João Pilatos (AMPPRJP), cujo presidente por ocasião da pesquisa chamava-se Lindomar de Souza e Souza. Na ilha inexistem serviços referentes a esgoto (a drenagem segue para os rios), coleta de lixo (os resíduos são queimados, enterrados ou depositados em área específica), assistência médica hospitalar (não possui infraestrutura para postos de saúde e farmácia, nem medicamentos em caso de emergência), água (o abastecimento da comunidade é feito por água pluvial, poços abertos e artesianos), segurança ( não há postos de polícia nem bombeiros, há apenas o Serviço de Polícia Marítima do Estado, que age por meio de denúncias para a base da Polícia Fluvial) e comércio (os alimentos industrializados são comprados e transportados de barcos, da cidade de Ananindeua para a llha).

Neste texto a ideia de lugar está associada tanto a sua dimensão físico-geográfica, como aos seus aspectos socioculturais. Dessa forma, considera-se a comunidade de llha Grande como"um lugar [que] é organizado por uma série de procedimentos denominada de estratégias" (CERTEAU, 2000, p. 202). De acordo com Diniz (2012), o lugar é criado a partir de laços afetivos e amorosos com os espaços físicos, é ponto de construção de subjetividade. Portanto, o lugar decorre de relações sociais e sentimentais fundadas com os ambientes.

Qualquer lugar vivido e imaginado "possui um vasto manancial simbólico [...] com os seus espaços de culto, os seus altares e, inversamente, os seus interditos" (SOUZA, 2011, p. 181). A percepção e uso local ou externo dos mananciais materiais e simbólicos e de seus potenciais socioculturais, ambientais, linguísticos, passam necessariamente por processos de identificação e visibilização de algumas das suas características e de esquecimento ou desvalorização de outras. Processos que guardam relação com a história do lugar, embora nem sempre usadas para a construção mais ampla de um imaginário atrativo de pertencimento. 
Do ponto de vista físico a comunidade de llha Grande, organizou-se a partir do campo de futebol, as casas foram construídas em sua volta. Trata-se de uma área que assume o significado de espaço de sociabilidade, porque além da prática do futebol, é nele que são realizadas as festas em homenagem aos santos padroeiros ou de sentido cívico. Nesse espaço também funciona a única taberna que atende a comunidade local e visistantes da Ilha. Em geral, é na taberna que são contratadas as refeições para equipes de trabalho ou turistas.

Além do campo de futebol também foi construída a Igreja e a Escola de Ensino Fundamental. Como espaço de sociabilidade são realizadas algumas festividades como o Carnaval, o Círio da llha que ocorre no mês de dezembro, o Festival do Açaí, relizado no mês de novembro e do Camarão. A hospitalidade e a simplicidade de seus moradores são alguns atrativos e motivos que a ilha oferece.

As casas, em geral, são de alvenaria, com número reduzido daquelas que são de madeira. Embora haja variações na arquitetura, o padrão aproximase das residências urbanas. Os cômodos são diferenciados, de acordo com a sua funcionalidade: sala, quarto, cozinha. O banheiro nem sempre é privativo. Em algumas casas foi possível observar que o trabalho praticado pela família é feito internamente, assim como a guarda de apetrechos de pesca e da prática da agricultura.

Portanto, seus modos de vida e formas de organização social e para o trabalho dão conta de uma preocupação com biodiversidade e ecossistemas a que estão associados. Constatou-se que, como em toda a Amazônia brasileira, a comunidade participante deste estudo estabelece uma diversidade de formas de contato e relação com os recursos advindos do solo, dos rios e das matas. Contudo, há evidências de compreensão de que essa disponibilidade torna-se condição necessária e indispensável à sua própria reprodução social.

\section{SABERES DO TRABALHO INSCRITOS NA DIVERSIDADE PRODUTIVA}

a espacialidade da ilha de João Pilatos configura-se por meio de suas territorialidades socioeconômica, política, cultural, ambiental e a pluriatividade estrutura a dinâmica produtiva local. O trabalho praticado nessas territorialidades ultrapassa sua dimensão econômica e assume papel de mediador na relação ser humano natureza e na reprodução social dos grupos locais. Configura-se, portanto, como espaço por onde circulam saberes conformadores de práticas de vida.

Contudo, esse trabalho pelas comunidades incorpora formas de organização e produção, que embora não estejam sustentadas pela 
lógica capitalista, dão conta de uma diversidade de relações históricas atravessadas por ancestralidades que têm reconhecido a "necessidade de elaborar e difundir concepções de mundo, conhecimentos e habilidade, padrão de conduta moral e projetos sociais, adequados aos seus interesses" (GRZYBOWSKI, 1986, p. 51).

Para mapear e analisar as formas de organização e produção que as comunidades estabelecem para o desenvolvimento de suas atividades produtivas torna-se necessário reconhecer que essas comunidades são dotadas de saberes que possibilitam a construção e uso de seus próprios "arranjos tecnológicos", necessários ao desenvolvimento de suas práticas produtivas.

Dessa forma, a relação do ser humano com a natureza, mediada pelo trabalho produtivo, sustenta-se no pressuposto de que a natureza por meio de seus diversos elementos propicia para os seres humanos e não humanos, as condições necessárias à reprodução material e simbólica da vida, em uma estreita relação com a natureza.

Mesmo porque as diversas territorialidades em que se efetivam as práticas de trabalho de mulheres e homens de João Pilatos são construídas por uma ordem cultural, que não é meramente expressão da natureza sob outra forma. Ao contrário, a ação da natureza se desdobra nos termos da cultura, isto é, sob uma forma que não é mais a sua própria, mas sim incorporada como significado. E o fato natural assume, portanto, uma nova forma de existência, [...] como fato simbólico.

Assim, nas comunidades insulares a vida conforma e é conformada por uma diversidade de práticas de trabalho:"o ilhéus pratica, quase sempre, a pesca, agricultura seja de terra firme ou de várzea e coleta extrativa" (Liderança Local, entrevista, 2014). Além do artesanato, de pequenos comércios ou da produção de carvão. Trata-se de experiências de "trabalho associado", no dizer de Tiriba (2006) nas quais os trabalhadores, seja por meio de suas unidades familiares, ou de práticas coletiva, tratam diretamente dos processos organizativos e produtivos do trabalho, ou seja, apropriam-se da totalidade de suas experiências produtivas, contrapondo-se às estratégias do modo de produção capitalista, que fragmenta e parcializa as formas de organização e produção, nas quais os trabalhadores dão conta apenas de funções específicas no sistema produtivo.

Ao tentar padronizar as atividades em agricultura e na coleta extrativa, as políticas oficiais desconsideram os múltiplos saberes, fazeres e formas de manejo dos recursos naturais desses grupos sociais. E ao desconsiderarem a lógica da pluriatividade que dinamiza o universo do trabalho local, essas 
políticas subsumem a ideia de que seus espaços de trabalho são dinamizados por suas vivências e convivências, por meio das quais relacionam processos educativos com estratégias de sobrevivência.

Nesse sentido, embora suas experiências de trabalho respondam em grande parte expectativas distintas e individuais da vida dos trabalhadores na comunidade, as formas de produzir diferem paradoxalmente da rotina de trabalho no padrão capitalista, porque elas estão assentadas em valores da tradição ciclos da natureza e, em face de sua especificidade humana incorpora uma dimensão educativa.

O princípio educativo do trabalho deriva dessa sua especificidade de ser uma atividade necessária desde sempre a todos os seres humanos. O trabalho constitui-se, por ser elemento criador da vida humana, num dever e num direito. Um dever a ser apreendido, socializado desde a infância. Trata-se de aprender que o ser humano enquanto ser da natureza necessita elaborar a natureza, transformá-la pelo trabalho, em bens úteis para satisfazer as suas necessidades vitais, biológicas, culturais etc.. Mas é também um direito, pois é por ela que pode recriar, reproduzir permanentemente (FRIGOTTO, 2001, p.74).

As práticas de trabalho desenvolvidas pela comunidade estudada configuram-se como experiência educativa que está para além da tradição pedagógica, pois segundo Bondía (2002, p. 20), o saber da experiência "se adquire no modo como alguém vai respondendo ao que lhe vai acontecendo ao longo da vida e no modo como vamos dando sentido ao acontecer do que nos acontece".

Desse modo, homens e mulheres ilhéus tornam-se sujeitos históricos de suas experiências, e para formatá-las esses sujeitos acionam uma variedade de elementos culturais que conformam seus saberes e suas experiências, dentre eles o trabalho, que para Bondía $(2002$, p.24) se constitui como uma atividade que tem a capacidade de dar condições aos sujeitos de inovarem, partilharem interesses e perspectivas, e de forma coletiva buscarem "conformar o mundo, tanto o mundo 'natural' quanto o mundo 'social' e 'humano', tanto a 'natureza externa' quanto a'natureza interna', segundo seu saber, seu poder e sua vontade".

As mulheres e os homens trabalhadores da Ilha de João Pilatos por meio de suas práticas de trabalho se constituem não só como os sujeitos da sua força de trabalho, mas também sujeitos de experiências engendradas por meio de seus saberes e habilidades profissionais que possibilitam dinamizarem seu cotidiano, construir e fortalecer suas relações sociais, conformarem suas vidas e dar sentido a sua existência, ainda que em um contexto localista da existência humana. 
Nessa reflexão, a ideia de cotidiano assume o sentido epistemológico atribuído por Heller (2004, p.17), ao considerar que

a vida cotidiana é a vida do homem inteiro, ou seja, o homem participa na vida cotidiana com todos os aspectos de sua individualidade, de sua personalidade. Nela, colocam-se "em funcionamento" todos os seus sentidos, todas as suas capacidades intelectuais, suas habilidades manipulativas, seus sentimentos, paixões, ideias, ideologias.

Os saberes inscritos nas experiências de trabalho de mulheres e homens ilhéus configuram-se como uma referência cultural importante à concretude da vida, porque se constituem ao mesmo tempo como processo e produto fincados em relações históricas que se materializam na cotidianidade e engendram processos educativos por meio do partilhamento desses saberes, dando sentido e concreticidade ao seu modo de vida e a sua práxis (KOSIK, 1995).

Nesse contexto, tento trazer ao debate práticas culturais que revelam relações de educação e trabalho, buscando dar conta da especificidade dos processos educativos que estão inscritos em experiências de trabalho de grupos sociais locais, neste caso, de uma comunidade insular, situada no interior da Amazônia Paraense, em cujos espaços circulam saberes, visando mapear os processos educativos que perpassam suas ações e práticas de trabalho.

Este tipo de comunidade pode ser nomeada como tradicional. A esse respeito Diegues (2004, p.85) pontua que:

Um aspecto relevante na definição de culturas tradicionais é a existência de sistemas de manejo dos recursos naturais marcados pelo respeito aos ciclos naturais, a sua exploração dentro da capacidade de recuperação das espécies de animais e plantas utilizados. Esses sistemas tradicionais de manejo não são somente formas de exploração econômica dos recursos naturais mas revelam a existência de um complexo de conhecimentos adquiridos pela tradição herdada dos mais velhos, de mitos e símbolos que levam a manutenção e ao uso sustentado dos ecossistemas naturais.

Percebe-se que no complexo de saberes que são construídos a partir do conhecimento ancestral, estão imersos os significados da experiência dos mais velhos da comunidade, formas de manejo intimamente associados aos ciclos da natureza, que revelam saberes e respeito em relação à natureza, que é tomada como um imperativo para a vida.

\section{SABERES DO TRABALHO INSCRITOS NA RELAÇÃO COM A BIODIVERSIDADE}

Situada na parte insular do municipio de Ananindeua, na área estuarina do rio Maguari, que organiza diferentes territórios ao longo de 
suas margens e se constitui como uma via importante para a circulação dos moradores ilhéus e/ou ribeirinhos, a ilha João Pilatos conta com um ambiente rico em biodiversidade, com o qual os seus moradores construíram uma singular identidade territorial, pautada em relações que estabelecem com a mata e com as águas, por meio de práticas históricas de manejo, através das quais tem construído diversos conhecimentos e saberes, dentre eles, àqueles relacionados aos seus ambientais, formas de manejo dos recursos naturais.

Sem dúvida, podemos dizer que existe uma grande quantidade de saberes produzidos no trabalho associativo e na vida cotidiana da classe trabalhadora - saberes estes que precisam ser explicitados e legitimados pelos próprios trabalhadores associados (TIRIBA 2006, p. 120).

Construídos no convívio do dia-a-dia, esses saberes configuram-se numa modalidade de educação voltada para a "cultura do Trabalho" (TIBIRA, 2006, p.121), que sem livros, sem professores e distanciados dos conteúdos dos currículos institucionais, são experimentados cotidianamente por meio de práticas de aprendizagem e processos cognitivos, que contribuem para a compreensão do mundo dos seus sujeitos.

Por meio desses saberes, pautados em uma ancestralidade e historicamente construídos, mulheres e homens trabalhadores dão conta e explicam a relação que estabelecem com os rios e matas, fontes importante de alimentos, seja por meio da variedade de espécies de peixes (bacú, piracema, pescada, dentre outros), das frutas típicas (jaca, açaí, bacuri, cupuaçu, ingá); ou da matéria-prima que é usada para a produção de artefatos ou produtos vegetais, como os cipós de guarachama, a samambaia e a argila que são aproveitados para produzir artesanato.

Dessa forma, a terra, os rios, as matas ocupam uma posição ímpar na estruturação dos diferentes espaços que conformam as territorialidades de trabalho locais. Inteiramente associados à perspectiva de reprodução social da comunidade local, esses ecossistemas assumem um sentido de vida, cuja centralidade para a sobrevivência, implica na construção de uma consciência coletiva voltada para a (re)configuração de seus modos de vida frente aos silêncios e exclusão na história oficial.

Os saberes inscritos nas experiências de trabalho das unidades familiares pautadas quase sempre na relação com a natureza e no manejo de seus recursos têm garantido a reprodução social e cultural dos sistemas locais. A partir dos saberes e dos conhecimentos sobre os elementos espaciais como os encontrados no solo, no rio, nas matas, os moradores criam e recriam suas condições de existência e reprodução. 
A reprodução social e simbólica pautada no manejo e exploração dos diversos ecossistemas indicam as múltiplas significações que o trabalho assume no cotidiano de mulheres e homens associados na AMPPRJP. É na relação com os diversos ecossistemas que diversidade de práticas produtiva é dinamizada no cotidiano social da ilha de João Pilatos. Trata-se de práticas produtivas que se assentam sobre outra lógica relacional com as matas, com os rios e com as águas. Trata-se de uma lógica culturalmente movida sob a égide da vida emocional, na qual o universo simbólico está integrado, capaz de promover uma interação ser humano natureza menos predatória e mais harmoniosa.

Por essa perspectiva, as experiências de trabalho local são mediadas por uma razão cultural (SAHLINS, 1979), que articula formação humana, diversidade cultural, elementos naturais, possibilitam o manejo de recursos extraídos do meio físico que são utilizados nas suas práticas produtivas, necessárias à sua subsistência. Essa mediação cultural conformam processos educativos, que como

um conjunto de conhecimentos e valores que se plasmam nos processos produtivos associativos, nas cooperativas, nos empreendimentos solidários, nas organizações econômicas populares, a cultura do trabalho vai se constituindo carregando elementos étnicos, religiosos, quer dizer, de elementos culturais e, inclusive, afetivos, que vão para além do processo de trabalho propriamente dito (TIBIRA 2006, p. 120).

Dessa forma, as relações que as mulheres e homens estabelecem com os rios e matas são conformadas por saberes que esses sujeitos, historicamente têm construído por meio de suas experiências, oralidades e relações que estabelecem uns com os outros e com os diferentes ecossistemas, ou seja, são saberes que são produzidos na vida cotidiana. O que evidencia a relevância dos saberes socialmente construídos e/ou mobilizados nas suas práticas de trabalho, inscritos na relação ser humano-natureza.

As unidades familiares usam a mata para a coleta de frutos, que em geral são aproveitados sob a forma de polpas, especialmente do açaí e do cupuaçu, que são levadas ao mercado de pequena escala; de sementes e raízes, extração de óleos (copaíba, andiroba etc.), usados como remédios caseiros e/ou alimentação em geral, e em alguns casos, também para extração de madeiras.

Em relação à prática da pesca, informações locais dão conta de que o trabalho na pesca artesanal tem enfrentado dificuldade em razão da diminuição do estoque pesqueiro, ou seja, devido à escassês de peixes. Questionado sobre essa dificuldade relatada pelos moradores, seu Osmarino, 
uma liderança local, identificou alguns fatores que estão, de acordo com a sua percepção, associado à racionalidade do processo de captura e uso dos rios:

Na realidade é o aumento da população. Eu penso assim né, e também do consumismo, muitas pessoas vem tirar de longe de seus barcos e rabetas. Também o barulho de motores que espanta os cardumes de peixe natural. São muitos barcos grande, aquelas iates que passam ali, que vem movimentando as aguas. Eu sei que isso é bom pra nós, o pessoal chega por aqui, mas isso espanta os peixes dos rios, principalmente aqui, entendeu?! O peixe não tá muito bom não (Entrevista, 2014).

Em face da natureza sazonal da maioria das atividades, há alternância entre os períodos da pesca, extração do açaí, produção do carvão e desenvolvimento da agricultura. Algumas atividades são praticadas de forma frequente no segundo semestre do ano devido à redução das chuvas. No primeiro semestre, vive-se o período do inverno regional, no qual ocorre uma queda acentuada na coleta do açaí, em face da entressafra e na produção do carvão em decorrência das constantes cheias dos mangues. $O$ manejo agrícola é quase que suspenso. Vive-se a abundância das frutas regionais (cupuaçu, bacuri, taperebá).

O inverno modifica tudo né! O açaí no verão? O que é que a gente tem? O açaí. Já vem outra marca do camarão. Já vem outra marca de peixe. E no inverno, quando chega o inverno já muda. Já o açaí não tem mais. Às vezes as frutas já acabaram. Já vêm outras safras de frutas. Só de setembro em diante que começa a safra do açaí. Aí o peixe já muda também. Tem o peixe do inverno e tem o peixe do verão. Ainda tem tudo isso (Entrevista, 2014)

Com as chuvas, há o aumento das atividades de pesca artesanal feita com o uso de linhas e anzóis intitulados de "espinheis" e redes artesanais denominadas "malhadeiras". O período chuvoso para Dona Maria Luíza representa a chegada da fartura, "a chuva traz camarão, peixe. Quando não chove tanto dá peixe, mas diminui mais. Aqui na terra a gente não precisa molhar nada, a chuva já se encarrega de molhar".

As cheias do rio Maguari proporcionam satisfação nos momentos de lazer, banho e uso das águas nos poços escavados nos quintais em decorrência da elevação do nível da água:

O rio é importante pra comunidade. Se nós quer conseguir alguma coisa nós pega o barco vai no Curuçambá. Vamos no rio e joga a malhadeira e pega o peixe, nós praticamente tira nosso sustento daqui, nós vamos lá pega o peixe, nosso camarão, é importante mesmo A gente quer tomar um banho no igarapé, só é correr daqui, muda o short e pêia no igarapé, é muito fácil 
pra nós. A gente quer jogar uma bola e depois toma no igarapé. É muito importante esse igarapé pra nós (Entrevista, 2014).

Sabedores da importância dos rios e igarapés para a reprodução social e sobrevivência econômica, os moradores da ilha assumem no seu cotidiano determinadas práticas culturais como necessárias à sua preservação, como a queima em seus quintais de resíduos domésticos, porque entendem que se depositados de forma incorreta nos terrenos terá como destino final, pela ação dos ventos e das chuvas, o depósito nos igarapés e córregos, com sérios comprometimentos nos ecossistemas da biodiversidade.

O cuidado com a conservação das águas ocorre dentre e fora do rio, conforme relato de D. Luíza, em 2014, que quando realiza seus deslocamentos por meio de canoas e rabetas costuma recolher lixo depositado no rio:

"Quando eu posso e que eu desço por aí e vejo muito saco de lixo, quando eu posso eu coloco alguns pra dentro da canoa e quando eu desço do rio eu queimo. Sempre eu faço isso. E até Graças a Deus está diminuindo".

Para os moradores, a mata é tida como o espaço dos mistérios e magias, das lendas. A mata é visualmente perceptível, mas ninguém desafia as suas incertezas. Segundo as crenças locais, a mata pune, enfeitiça, assombra. Ainda assim, dá prazer, acalenta, conforta e abriga.

A diversidade de práticas produtivas que demanda o manejo dos recursos da natureza, segundo a lógica local, é marcada pelo desenvolvimento de um processo de aprendizagem contínua ao longo das gerações. As práticas cotidianas de manuseio da terra, o plantio de sementes, a coleta de frutos, a escolha de vegetais, raízes e lascas de árvores representam um conjunto de procedimentos e saberes aprendidos e socializados intergeracionalmente.

A apropriação e uso dos recursos da natureza para o desenvolvimento de práticas produtivas, quase sempre é para o sustento do grupo familiar, em alguns casos, com a comercialização do excedente.

Entre os ilhéus há um consenso entre eles de que a natureza pode ser usada, mas precisa ser protegida para a continuidade de suas vidas, suas estórias e culturas sejam asseguradas.

Para sobreviver nós usamos o açaí, a gente vai lá apanha, amassa pra tomar aquele açaí. O carvão, nós também somos obrigados a ir lá tirar uma fornada para nós pode usar no fogão. Não chegar lá e cortar, explorar né. A gente não vai também estragar, a gente corta e vai vender, vai vender e compra outra coisa, compra a farinha (RDF, Entrevista em 2012). 
Os saberes tradicionais foram apropriados a partir do trato com a terra, com as águas e com a mata, ou seja, na oralidade, através das falas e repetição de ações que se configuram como procedimentos a serem imitados pelos mais novos, os aprendizes. Um dos entrevistados destaca as práticas de aprendizagem sobre o trato da mata e da terra para saber-fazer uma roça, cujos procedimentos demandam observação, manuseio e internalização de saberes socializado na comunidade:

A gente vai na roça, vai tira ali uma parte do terreno, nós vai roça tudinho bacana, aí quando secar tudinho o mato, então tem fazer no verão, no inverno não presta, tem que ser no verão mesmo forte aí toca fogo. A gente toca fogo nos galhos tudo e aí vamos pegar a maniva e cortar todinho em pedacinho a maniva e cavar, em cada buraco nós coloca dois pedaços de maniva, aí vai tapa aquele buraco, aí com um mês, dois meses tá nascendo. Aí plantou e depois que tu plantar tem que trazer todo aquele lixo pro tronco dela e aí com seis meses do toma na capina, a mesma coisa (RDF, Entrevista,2014).

No relato fica evidente o cuidado com a natureza mesmo naquelas práticas cotidianas que envolvem algum tipo de predação, como o cultivo da roça, a pesca, o extrativismo do açaí, entre outras. Os moradores relataram que procuram desenvolver suas atividades socioeconômicas de modo que não comprometam a preservação da natureza.

Os produtos nativos conformam um cenário de cheiros e sabores na paisagem do lugar. O marrom das águas barrentas contrasta com o verde das matas, que é matizado pelos traços coloridos das pequenas embarcações que passam pelo igarapé e das casas e escola, na terra firme. $O$ cheiro no ar varia de acordo com a época do ano. O cheiro exótico do cupuaçu ou adocicado do bacuri marca o denominado período invernoso da região (dezembro a abril, aproximadamente).

Os moradores relataram que além da dificuldade dos deslocamentos até os lugares de maior circulação de pessoas, não têm apoio para fazer o escoamento do pequeno excedente do que colhem e coletam. No depoimento de seu Osmarino (Entrevista, 2014) é possível identificar essa dificuldade:"nós não temos aonde colocar, porque o consumo ele ainda é pouco. Quando se colhi, prepara-se e quer se vender, entendeu? pra um, ou outro, né?".

Dessa forma, percebe-se que a diversidade de práticas produtivas, ao mesmo tempo em que informam os modos de vida e revela as interações que as comunidades rurais-ribeirinhas exercem com os elementos existentes na natureza e com seu entorno, indicam as dificuldades que enfrentam cotidianamente para garantir a sobrevivência material e a valorização da cultura local. 
Durante as entrevistas, por exemplo, perguntamos para alguns moradores sobre qual era o significado da mata, do rio, sobre a importância dos saberes que eles têm sobre o uso dos seus recursos.

A importância pra mim é na realidade a coisa mais linda né, principalmente porque eu vim da cidade há dois anos atrás, o meu pai faleceu nessa área aqui, que pertencia ao meu pai e minha mãe eu moro bem ai, ai o meu pai liberou, me deu antes de falecer né, uma parte lá atrás ai veio o governo federal é assim nos deu uma parte, um titulo de posse na realidade a gente espera como posseiros ilegais né, agora todo mundo é legalizado né pelo, pelo... E pra mim, pela natureza pela área que estou hoje, do barulho né, na realidade pra mim é outra realidade.

Essa narrativa indica que, em geral, eles reconhecem que esses legados da natureza fazem parte e revelam muito da história do lugar e que tem um papel solidificador de suas vidas.

O respeito pelos lugares é demonstrado pelo cuidado com a limpeza dos quintais e das trilhas da comunidade, não havendo acúmulo de lixo ou entulhos. A manutenção de árvores e plantas nativas e a retirada não predatória dos recursos naturais traduzem o respeito pela natureza que também é tida como fonte para fabricação dos mais variados remédios.

É por meio de seus saberes e processos educativos que as comunidades que se encontram distantes do centro urbano, resistem pressões da mídia global que tenta impor localmente valores da sociedade de consumo, e mantém formas de manejo e uso da natureza, que assume significados muito particulares, que contrariam a lógica capitalista, que muito têm contribuído para a desestruturação socioecológica na região amazônica.

\section{A PRESENÇA DOS SABERES LOCAIS NA ESCOLA}

A concepção de educação sustentada nas teorias educacionais desenvolvidas por Brandão (2002) e Freire (1993), nas quais a educação configura-se mais como um elemento da cultura, serve de fundamento para compreender que comunidades da ilha de João Pilatos, por meio de suas experiências de trabalho constroem processos educativos singulares que podem contribuir para o processo formativo das identidades individual e coletiva dos agrupamentos humanos do campo.

$\mathrm{Na}$ realidade estudada, ainda que os saberes das experiências de trabalho não integrem o desenho curricular, eles estão inseridos na agenda escolar como uma prática cultura sistemática e efetiva. Não se trata de iniciativas individuais e/ou instrumental, porque aqueles saberes que se 
constituem numa prática pedagógica específica, que ocorre nos espaços de trabalho do campo são colocados em interação com processos educativos cotidianos da escola local.

Na comunidade de Igarapé Grande, saberes das experiências de trabalho e educação do campo constituem elos por meio de um processo de partilhamento de conhecimentos e práticas. "A práxis, porém, é a ação e reflexão dos homens sobre o mundo para transformá-lo" (FREIRE, 1983, p. 40). Dessa forma, tal como a perspectiva freiriana, a educação do campo é pensada e praticada a partir do contexto sócio-histórico, natural e cultural dos sujeitos. Essa educação não se limita à prática e reflexão pedagógica da escola formal, está presente no cotidiano dos sujeitos da comunidade.

Esses elos entre saberes das experiências de trabalho e àqueles dinamizados pedagogicamente nos espaços da escola da comunidade, remetem para uma concepção alargada de educação, na qual educar é dar sentido à própria vivência, compreender o funcionamento da sociedade, e dar sentido ao mundo. Portanto, orientando pela concepção freiriana (1983), educar é considerar a diversidade de saberes, aprender a ler o mundo de forma crítica e compreender que os seres humanos são sujeitos inacabados e que estão num processo contínuo de transformação.

Assim, as experiências de trabalho dinamizadas por mulheres e homens ilhéus, conformam espaços educativos, cujos processos em contextos locais podem ser reconhecidos como possibilidades de resistência frente à ausência do Estado na implementação de políticas sociais nas comunidades que ficam mais "distantes" do centro da capital Belém.

Os espaços coletivos de trabalho assumem centralidade nos processos de resistências, como é o caso dos mutirões, por meio dos quais os participantes criam e recriam na relação entre si e com a natureza, formas de compreensão e leitura do mundo na perspectiva de alcançarem autonomia na luta política para a resistência, conforme indicações da educação pensada por Freire (1993), frente à imposição dos agentes capitalistas, que nessas "áreas longínquas", aproveitam-se da ausência do estado para impor modelos predatórios de exploração dos recursos naturais, como é o caso da madeira e da argila.

Na dinamização de suas práticas de trabalho, mulheres e homens ilhéus, a natureza além de representar um dos locais de culto, é um espaço de circulação de saberes, configurando-se dessa forma como um território educativo, ampliando a ideia de que os espaços educativos não estão limitados aos ambientes escolares, e que não podem mais ser vistos como os únicos espaços por onde circulam saberes e práticas pedagógicas. 
A escola local, não só por causa de suas práticas de educação formal, é um espaço de referência importante para a comunidade, nela também circulam saberes locais, tidos pelos docentes como fundamentais na construção da identidade territorial dos estudantes, assim como para a sobrevivência de seus valores e crenças.

Com aspecto bem conservado, a escola estabelece uma comunicação direta com o rio. A mediação entre ela e o rio se materializa por meio de um trapiche de madeira, pintando e bem conservado. Quem chega pelo rio, ao saltar da canoa é recebido pela escola. Ela está ali, identificada imediatamente por uma grande mandala de madeira nativa, de braços abertos dando as boas vindas. Uma grama rústica bem "tratada", revela cuidados com sua manutenção e conservação.

Ao chegar-se no trapiche, uma enorme legenda na parede identifica a escola e revela a peocupação com natureza: EMEF DOMICIANO DE FARIAS - MA E A RESPONSABILIDADE DE CUIDAR. “Pois dos rios faço a minha estrada e das matas faço as minhas trilhas".

No interior da escola, nas salas de aulas, as placas de ientificação dão conta da identidade ribeirinha: "Pré-I/Ribeirinho l; Pré-II/Ribeirinho II. No "Cantinho da Leitura” algumas legendas: “Esse rio é minha rua”, "Plante uma árvore, semei paz", “Onde tem água limpa, tem vida”.

Nos corredores, lixeiras rústicas construídas com cipós coletados na natureza e fabricadas na própria escola, por meio de ensinamentos dos "mais velhos da comunidade". Os cestos além de coletarem o lixo, dão um tom estético na área. Não foi verificado nenhum tipo de ação depredadora da escola, como por exemplo, pixação, mobiliários quebrados, etc.

A escola reflete de alguma forma no seu interior a cultura e os saberes das experiências da comunidade impressas por meio de suas práticas de trabalho, de suas celebrações e festas, datas cívicas, na sua estrutura física e outras práticas pedagógicas.

Conclui-se, portanto, que a escola na sua função social, articula por meio de suas práticas pedagógicas e da organização do seu ambiente físico, saberes locais que são dinamizados por meio das experiências de trabalho, promovendo, dessa forma, um diálogo intercultural entre os saberes locais e as práticas pedagógicas da escola, o que contribui ativamente para assegurar boas condições ambientais, valorização do conhecimento nativo em relação ao uso dos recursos da floresta e dos rios na reprodução material e simbólica da vida, assegurando a continuidade dos modos de vida, crenças locais e o fortalecimento da identidade cultural por meio das práticas de uma escola do campo. 


\section{KNOWLEDGE AND EDUCATIONAL PROCESSES IN WORK EXPERIENCES IN ISLAND TERRITORIES}

ABSTRACT: This research seeks to analyze knowledge and educative processes embedded in work experiences promoted by Association of Rural Residents and Small Producers of João Pilatos (AMPPRJP), which in social daily life inform relations with local biodiversity, examining perspectives of dialogue with rural scholar practices. It is an Amazonian island community, whose territorialities are reminiscent of ancestry that takes place through an intense and systematic relationship with nature, which is not always recognized and considered by public policies. Methodologically, we choose for historical materialism, using semi-structured interviews. The results of the research indicate the work centralism as a way of survival of the family group, whose productive practices are permeated by educative principles and constitute spaces for the circulation of knowledge, experiences and sociabilities of the social groups of the community and promote positive impact in their realities and approach and dialogue with the local school.

KEYWORDS: Work knowledge. Educational process. Ancestral Territoriality. Biodiversity.

\section{SABERES Y PROCESOS EDUCATIVOS EN LAS EXPERIENCIAS DE TRABAJO EN TERRITORIOS INSULARES}

RESUMEN: Se busca analizar los saberes y procesos educativos asentados en experiencias de trabajo dinamizadas por mujeres y hombres que integran la Associação dos Moradores e Pequenos Produtores Rurais de João Pilatos (AMPPRJP), que en el cotidiano social informan relaciones con la biodiversidad local, examinando perspectivas de diálogo con prácticas educativas escolares del campo. Se trata de una comunidad insular amazónica, cuyas territorialidades guardan memorias de una ancestralidad que se desarrolla por medio de una relación intensa y sistemática con una naturaleza, no siempre reconocida y considerada por las políticas públicas. Metodológicamente se optó por el materialismo histórico, con el uso de entrevistas semiestructuradas. Los resultados de la investigación indican la centralidad del trabajo como un medio de supervivencia del grupo familiar, cuyas prácticas productivas están embebidas de principios educativos y se constituyen en espacios de circulación de saberes, de vivencias y sociabilidades de los grupos sociales de la comunidad y suscitan un impacto positivo en sus realidades y aproximación y diálogo con la escuela local.

Palabras clave: Saberes del Trabajo. Procesos Educativos. Territorialidad Ancestral. Biodiversidad. 


\section{REFERÊNCIAS}

BRANDÃO, C. R. A educação como cultura. Campinas: Mercado de letras, 2002.

BONDÍA, J. L. Notas sobre a Experiência e o Saber da Experiência. Tradução João Wanderley Geraldi. Revista Brasileira de Educação [on-line], Rio de Janeiro, n.19, p. 20-8, jan./ abr., 2002. Disponível em: <http://dx.doi.org/10.1590/S1413-247882002000100003>. Acesso em: 15 mar. 2012.

CERTEAU, M. de. A invenção do cotidiano, artes de fazer. 5. ed. Petrópolis, Rio de Janeiro: Vozes, 2000.

DINIZ, F. P. S. Relações entre Práticas Educativas, Saber Ambiental-Territorial Ribeirinho e o Desenvolvimento Local. 2012. 185 f. Dissertação (Mestrado em Educação) - Programa de Pós-Graduação em Educação, Universidade do Estado do Pará. Belém, 2012.

DIEGUES, A. C. (Org.). Enciclopédia Caiçara. v.1, São Paulo, HUCITEC: NUPAUB: CEC/ USP, 2004.

FRIGOTTO, G. (Org.) Teoria e educação no labirinto do capital. 2. ed. Petrópolis: Vozes, 2001.

FREIRE, P. Educação como prática da liberdade. 23. ed. Rio de Janeiro: Paz e Terra, 1993. .Pedagogia da esperança. Rio de Janeiro: Paz e Terra, 1983.

GRZYBOWSKI, C. Esboço de uma alternativa para pensar a educação no meio rural. Revista Contexto e Educação, n. 4, p. 47-59, out./dez. 1986.

HELLER, A. O cotidiano e a História. São Paulo: Paz e terra, 2004.

KOSIK, K. O mundo da pseudoconcreticidade e a sua destruição. In: . Dialética do Concreto. Rio de Janeiro: Paz e Terra, 1995.

LEFF, E. Saber ambiental: sustentabilidade, racionalidade, complexidade, poder. 7. ed. Petrópolis, Rio de Janeiro: Vozes, 2009.

SILVA, M. G. da. Saberes culturais e suas repercussões no uso dos recursos naturais. AmbientalMente Sustentable. Coruña/Galicia, v. 2, n. 20, p. 1781-98, 2015.

SILVA, M. G. da.;TAVARES, M G. da C. Saberes Locais e Manejo Sustentável dos Recursos da Floresta. In: III ENCONTRO DAS ANPPAS, 2006, Brasília, DF. Anais...2006.

SILVA, M. G.; et. al. Cartografias e métodos (s): outros traçados e caminhos metodológicos para a pesquisa em educação. In: MARCONDES, M. I; TEIXEIRA, E.; OLIVEIRA, I. A. de. (Org.). Abordagens teóricas e construções metodológicas na pesquisa em educação. Belém: Eduepa, 2011.

SAHLINS, M. Cultura e Razão Prática. Tradução Sergio Tadeu Niemayer Lamarão. Rio de Janeiro: Jorge Zahar, 1979. 
SOUZA, M. J. L. de. OTerritório: sobre e espaço e poder, autonomia e desenvolvimento. In: CASTRO, I. E.; CORRÊA, R. L. (Org.).Geografia: conceitos e temas. 3. ed. Rio de Janeiro: Bertrand Brasil, 2011.

TIRIBA, L. Cultura do trabalho, produção associada e produção de saberes. Revista Educação Unisinos, São Leopoldo, v. 10, n. 2, p.116-122, maio/ago. 2006.

Maria Graça Silva: Professora do Departamento de Filosofia e Ciências Sociais (DFCS) e Programa de Pós-Graduação - Mestrado em Educação, Centro de Ciências Sociais e Educação (CCSE-UEPA).

E-mail:magrass@smail.com 